\title{
Variances in proto-dolomite formation by exopolymers from oxygenic, and anoxygenic microbial mats and clays
}

Maria Dittrich', Zach A. DiLoreto', Tomaso R. R.

Bontognali', Huan Liu ${ }^{3}$, Xiancai Lu

Biogeochemistry Group, DPES, University of Toronto, Toronto, Canada (mdittrich@utsc.utoronto.ca, zach.diloreto@utoronto.ca)

. Space-X Switzerland (tomaso.bontognali@space-X.ch)

${ }_{3}^{3}$ School of Earth Sciences and Engineering, Nanjing

University (liuhuan@nju.edu.cn, xcljun@nju.edu.cn)

For several decades, dolomite formation has remained a geological enigma, which can be defined as a discrepancy between the dolomite presence in the past and their scarcity in the modern environment, and the failed efforts to precipitate dolomite under low temperature less than $60 . \mathrm{C}$ in a laboratory. The accepted explanation of modern dolomite formation is that negatively charged carboxyl functional groups of extracellular polymeric substances (EPS) of microbial origin can serve as a template for dolomite. Liu et al. have shown that the negatively charged surfaces of clays catalyze dolomite formation [1]. In the environment, both biotic and abiotic pathways to form dolomite are present.

We performed kinetic experiments kaolinite and montmorillonites seeds and with EPS from oxic and anoxic phototrophic surface layers of microbial mats from hypersaline sabkhas. Our time-series results demonstrated stepwise recrystallization of calcium carbonate phases to proto-dolomites, or high-Mg-Ca carbonates formed initially as nanosized granules (Fig. 1A, B). Our results showed differences in kinetic of proto-dolomite formation between EPS from two microbial mats, as well as kaolinite and montmorillonites.
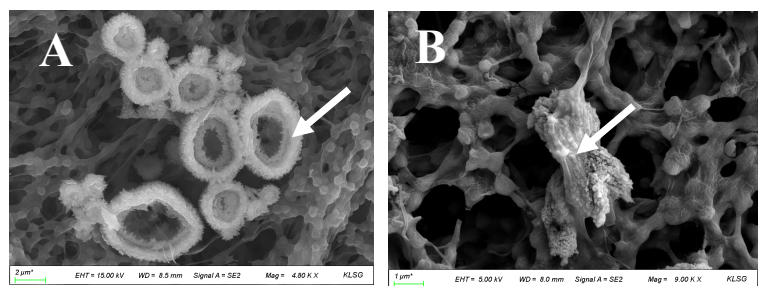

Figure 1. Carbonate (A) and high Mg-Ca carbonate formation (B) with EPS from the oxic phototrophic microbial mat.

[1] Liu, D., Xu, Y., Papineau, D., Yu, N., Fan, Q., Qiu, X., and Wang, H. (2019). Experimental evidence for abiotic formation of low-temperature proto-dolomite facilitated by clay minerals. Geochimica et Cosmochimica Acta 247, 83-95. 